ISSN: $1130-3743$

\title{
EL LENGUAJE DE LOS ESPACIOS: INTERPRETACIÓN EN TÉRMINOS DE EDUCACIÓN
}

\section{The language of spaces: interpretation in terms of education}

\section{Le langage des espaces: interpretation en termes d'éducation}

José Manuel MuÑoz RodRíguez

Universidad de Salamanca. Facultad de Educación. Departamento de Teoría e

Historia de la Educación. C/ Paseo de Canalejas, 169. 37008 Salamanca.

Correo-e: pepema@usal.es

Fecha de recepción: enero de 2005

Fecha de aceptación definitiva: abril de 2005

BIBLID [(1130-3743) 17, 2005, 209-226]

RESUMEN

Este trabajo presenta algunas de las formas a través de las cuales podemos entender los espacios no sólo como los lugares o sitios en que se desarrolla el proceso, la acción educativa, sino también como uno de los elementos básicos del proceso, capaz de proporcionar un lenguaje, distinto del tradicional, que nos permite descifrar e interpretar algunos hechos vitales de la especie humana.

El autor reconstruye uno de los soportes necesarios para pensar y hacer educación en los tiempos actuales, mostrando el significado y la comunicación más allá de la tradición individual, en base al significado social y competencia comunicacional de los espacios.

Palabras clave: pedagogía de los espacios, procesos primarios de formación, competencia comunicacional, lenguaje educativo. 


\section{SUMMARY}

This study presents certain ways to understand the spaces, not only as the contexts or places where the process takes place-educational action-but also as one of the basic elements of the process, able to provide a language -different from traditional one-which help us to decipher and interpret of the vital facts of the human being.

The author re-create one of the supports needed for thinking and making education nowadays, showing the meaning and the communication beyond the individual tradition, on the basis of the social meaning and communicational competence of the spaces.

Key words: pedagogy of the spaces, primary process of training, communicational competence, educational language.

\section{SOMMAIRE}

Ce travail présente certains formes à travers lesquelles nous pouvons comprendre les espaces, pas seulement comme les contextes ou endroits où le processus à lieu, l'action éducative, mais aussi comme un des éléments basiques du processus, capable de fournir un langage, différent de l'habituel, qui nous permet de décoder et interpréter quelques faits vitales de l'espèce humain.

L'auteur reconstruit un des supports nécessaires pour penser et faire l'éducation actuellement, en montrant la signification et la communication plus loin de la tradition individuelle, sur base de la signification social et compétence communicationnelle des espaces.

Mots clef: pédagogie des espaces, processus primaires de formation, compétence communicationnelle, langage éducative.

Todo cuanto sucede, cuando de educar a las personas estamos hablando, suele implicar, en mayor o menor medida, elementos comunicacionales, de lenguaje. El discurso generalizado en educación sobre el lenguaje y la comunicación ha estado centrado en el lenguaje interpersonal mediado, principalmente, por el uso de la palabra y, en algunos casos, con alusión a otro tipo de lenguajes, pero casi siempre en estricta referencia a la persona como elemento central del proceso (Redondo, 1999; Kaplún, 1998).

Nuestro propósito aquí, en cambio, es poner de manifiesto que existen elementos de lenguaje más allá de la piel del individuo. Si, por un lado, construir las identidades personales y colectivas es el objetivo de todo proceso formativo "y comprender ese proceso es el objetivo fundamental de la teoría de la educación" (García Carrasco y García del Dujo, 2001b, 41), y, por otro, el individuo lleva a cabo ese proceso en coderiva con realidades concretas, espacios vitales y relacionales, 
procede preguntarnos por los elementos significativos y comunicacionales que tiene precisamente esa realidad, los espacios de referencia ${ }^{1}$. Sin prescindir, por supuesto, de los elementos comunicacionales que muestra la persona, en los espacios por los que deambulan los sujetos pueden detectarse tramas comunicacionales adjuntas a las interpersonales cuya identificación y análisis redundaría en beneficio de los procesos que ahí tienen lugar, entre otros los procesos educativos.

Cuando se dice que la educabilidad del sujeto viene amparada por su capacidad de comunicación, entendida ésta en sentido amplio incluyendo también algunos elementos del sistema de comunicación animal, estamos implícitamente otorgando potencialidad educativa a los espacios en cuanto que conforman un sistema de señales codificadas culturalmente y compartidas por un grupo. Y ésta es precisamente la pretensión básica de este trabajo: hacer explícita e inteligible dicha potencialidad en la intención de usufructuarla en las prácticas educativas de la vida cotidiana ${ }^{2}$.

\section{La PEDAGOGÍa DE LOS ESPACIOS COMO ORIENTACIÓN EDUCATIVA}

Aunque nos vamos a detener a observar el hecho educativo desde una orientación concreta, no pretendemos defender de manera unilateral y ortodoxa una posición, como si el resto de formas de comprender los procesos y hechos educativos no tuvieran sentido ${ }^{3}$; mucho menos encapsular la acción educativa dentro de unos límites y menos aún clausurar territorialmente al sujeto. No es nuestro propósito defender ningún tipo de determinismo físico, biológico o ambiental. Al contrario, pretendemos ver y presentar con proyección pedagógica, a nuestro

1. "No se trata de una realidad desligada de la relación concreta con el hombre, sino del espacio tal y como existe para el hombre y, de acuerdo con ello, de la relación humana con este espacio, pues ambas cosas son imposibles de separar" (Bollnow, 1969, 25).

2. No es el momento de analizar con precisión el concepto de espacio, aunque sí procede alguna aclaración. Este término tiene numerosas acepciones, dependiendo del ámbito disciplinar en que se utilice, incluso dentro de un mismo campo adquiere sentidos diferentes; con frecuencia es sustituido por otros conceptos que aportan significados particulares.

Nuestra propuesta se apoya en una concepción de espacio global y abierta: magnitud extensa que da cabida al sujeto y al conjunto de acciones e interacciones que ahí se desarrollan; instancia multinivel -política, social, cultural, económica...- donde el sujeto se instala, al tiempo que se construye y adquiere su identidad; campo categorial integrado por otros muchos términos, como ambiente o conjunto de circunstancias que rodean al sujeto, contexto o condicionantes internos y externos del sujeto que forman la realidad física y social, medio o factores físicos, sociales, culturales, económicos, etc., que circundan al sujeto y se relacionan con él, así como la noción de lugar en cuanto territorio o espacio acotado donde se expresan las experiencias individuales y sociales, configurando todo ello un convoy terminológico que da forma y contenido a la semántica del espacio.

3. Coincidimos con el profesor Trilla en que "las ortodoxias pedagógicas tienden a sacralizar y disecar la herencia de los maestros y de los creadores y acaban funcionando mediante la exclusión. Las ortodoxias, en lugar de procurar que las buenas ideas y metodologías puedan fecundarse entre sí, enquistan a las propias e invalidan arbitrariamente las ajenas" (TRILLA, 2004, 10). 
juicio de interés en los tiempos que corren, al sujeto como persona contextualizada, al hecho educativo como acción y proceso con sentido y, en general, a la Pedagogía como ciencia social que considera el espacio sustrato básico de su estructura, más allá de las consideraciones que se han venido haciendo sobre los espacios físicos en educación.

Nuestro objetivo es indagar en el inevitable entramado espacial en el que conviven y se desarrollan las personas para encontrar ahí formas diferentes de hacer y pensar el hecho educativo. Defendemos que, cuanto mejores y mayores sean los referentes espaciales y territoriales, en mejores condiciones se llevarán a cabo los procesos educativos y de construcción de identidades. Interpretar y reordenar los espacios en este sentido supone contar con un lenguaje educativo distinto del tradicional.

\subsection{Perspectiva socioeducativa dominante}

Ha sido habitual concebir la educación como dinámica interpersonal, en la que los sujetos protagonistas de la acción han llevado la mayor parte del peso del proceso. Estamos acostumbrados a ver e interpretar la educación como un elenco de procesos, hechos y fenómenos de corte interpersonal, mediados por la palabra, haciendo prevalecer por encima de todo un enfoque básicamente personalista (García Carrasco y García del Dujo, 2001b), optando así por una orientación pedagógica anclada en los mismos orígenes de la modernidad y relegando a un segundo plano una de las partes esenciales del proceso: todo aquello que existe más allá de las fronteras del individuo.

También en educación ha prevalecido la cultura del individuo. Es la mente individual la que ha primado en los discursos y ha servido como lugar de explicación de los fenómenos (Wulft, 2004). Las creencias sobre el sujeto y su mente han supuesto la base de la mayoría de las instituciones habidas, olvidando que, si bien la formación y desarrollo del sujeto es el objetivo último, ahí podemos llegar no sólo desde los procesos unidireccionales, tradicionales, de educador-educando.

Igualmente, viene siendo un hábito generalizado utilizar como referencia fundamental del éxito de los procesos formativos, e incluso del éxito social, la variable inteligencia (Gould, 2003), hasta el punto de considerarla el recurso más utilizado para explicar y valorar los comportamientos óptimos o irregulares de la especie humana, tanto en el campo científico como dentro del ámbito cotidiano, lo que ha generado procesos de reconducción educativa excesivamente encaminados a la estructura mental del sujeto o su mayor o menor habilidad intelectual. Y ello, decimos, como consecuencia del ensalzamiento de la mente individual, su capacidad de ordenar, razonar, y su facultad para trascender o relativizar los desajustes provenientes de aspectos extraindividuales.

Pero no sólo nos hemos inclinado por la inteligencia como núcleo de comprensión y justificación de la acción, también de la acción educativa, sino que, en igual medida, nos hemos decantado por favorecer y asociar lo pedagógico al uso 
de técnicas e instrumentos que nos proporcionen resultados precisos, inminentes, objetivos.

La sociedad de nuestro tiempo avala esta perspectiva: una sociedad altamente tecnificada, concebida en términos de estructura y dinámica reticular, con fuertes tendencias a la homogeneización del pensamiento y de la acción, una sociedad gestionada a través de una morfología espacial cuyo análisis y valoración vienen descritos en términos de dominio y de razón técnica (Todd, 1999; Baumen, 2001).

Esta perspectiva dominante sobre lo educativo, la cultura y la sociedad, conlleva una infravaloración del espacio. De hecho, cuando analizamos el espacio en el que transcurren los fenómenos, no pasamos del análisis de sus elementos y naturaleza. El resultado es una visión de los espacios como meros escenarios o contenedores de las acciones a desarrollar, ignorando su papel en el proceso ${ }^{4}$.

\subsection{Mirando la educación desde otra perspectiva ${ }^{5}$}

La perspectiva socioeducativa que acabamos de mencionar puede verse reforzada o complementada por otras orientaciones, donde los espacios adquieran mayor protagonismo. No podemos seguir pensando que los espacios participan en el proceso de configuración de la identidad de las personas sin revisar y reconstruir el potencial educativo que aportan. Esto nos lleva a plantear la denominada Pedagogía de los espacios, como marco de referencia que fundamenta y justifica el lenguaje de los espacios y su valor educativo. Una perspectiva o línea de investigación que viene avalada, entre otros, por los siguientes argumentos:

De entrada, no es preciso reflexionar demasiado para argumentar que el sujeto, la persona humana, es un "ser espacial ${ }^{6}$. Es decir, todo cuanto realiza en su vida tiene relación directa con un espacio en el que queda referido. No sólo estamos en los espacios, lugares, ambientes o contextos, sino que también somos en un espacio, tenemos sentido dentro de unos espacios que otorgan significado, razón de ser en último término, o quizá primero, a nuestros sentimientos, relaciones y comunicaciones. Todo cuanto sucede en la vida de una persona lo hace en

4. No obstante, no debemos olvidar que han sido numerosos los autores que ya pusieron de relieve, de una u otra forma, la variable espacial, y cuyas fórmulas y proposiciones hemos de contemplar. Entre ellos podemos citar a María Montesori y su educación activa y sensorial, Pestalozzi y su educación elemental, Frances Ferrer i Guàrdia y la Escuela Nueva, John Dewey y la democracia vital, Célestin Freinet y el principio de cooperación investigativa, Lorenzo Milani y la escuela de Barbiana, Paulo Freire y su Pedagogía del oprimido, Vygotsky y su enfoque socio-histórico-cultural, etc. (AA.VV., 2000; Trilla, 2002).

5. Algunas de las ideas de este epígrafe han sido expuestas de forma más pormenorizada en un trabajo publicado junto al profesor García del Dujo, dentro del marco de un monográfico sobre Arquitectura y Educación, coordinado por la profesora Romañá Blay (GARCía DEL Dujo y MuÑoz RodríGuEz, 2004).

6. «Existimos en situación, existimos finitos. No hay modo de esquivarlo. Espacio y tiempo nos dejan situados" (Fullat, 2000). 
referencia a unas coordenadas espaciales. Dicho de otro modo, la persona humana no puede, y de hecho no suele estar, "a la intemperie", sin referencia espacial; su intima e irrenunciable configuración necesita, para tener sentido, poner espacios, sentirse espacialmente. Nuestra vida concreta y el lugar en el que se desarrolla aparecen directamente asociados, interrelacionados, complementados, no determinados (Zubiri, 1996; Arendt, 1996; Morales, 1999).

En consecuencia, el interrogante principal acerca del espacio es la condición del hombre en él, lo que nos conduce a un segundo argumento: los espacios son un elemento constitutivo del ser humano: si la persona es un "ser espacial", no menos cierto es que el espacio es un "fenómeno próximo" ${ }^{7}$, de convivencia, al sujeto, elemento constitutivo del ser humano (Bachelard, 1965; Augé, 1998a; Hall 1973; Delgado, 1999). Dos argumentos que discurren parejos, en esta ocasión observando el fenómeno desde la otra orilla, la espacial. Y es que los espacios fortalecen actitudes, pueden llegar a provocar otras, soportan debilidades y explican comportamientos. Tienen, en fin, el privilegio de poder ser también protagonistas en la vida cotidiana de las personas. Su proximidad respecto de los avatares diarios hace que necesitemos observarlos para reconstruirlos, si procede, desde el campo educativo.

Parece que existe acuerdo en el hecho de que estamos ante un tema marginado y de reconocimiento tardío y precario en la literatura pedagógica. La Pedagogía, como ciencia de la educación, no ha venido demostrando especial interés por la variable espacial en cuanto objeto propio y específico de investigación y análisis ${ }^{8}$. Comenzó a señalarse la preocupación por este tema en los años ochenta (Colom y Sureda, 1981; Sureda y Colom, 1989), si bien ha sido en la década de los noventa cuando el interés por el espacio va tomando cuerpo más allá de una interpretación didactista, organizativa y escolar (García Carrasco, 1992; Castillejo y otros, 1994; Romañá Blay, 1994; García Carrasco y García del Dujo, 2001a). No obstante, aún se sigue diciendo que ula categoría espacio, para la comprensión del fenómeno global de la educación, se trae a cuento con demasiada parsimonia" (García Carrasco, 2004, 229) o, con palabras de Romañá Blay (2004, 200), que «las potencialidades educativas de los lugares apenas han sido tratadas en la literatura españolaw.

7. A este respecto hay que hacer mención de la "proxémica" (HaLl, 1973), en cuanto modelo antropológico del espacio con el que coincidimos en algunos aspectos, que elabora una teoría acerca del uso cultural que hace el sujeto del espacio y cuya influencia está sobradamente demostrada. Resulta muy esclarecedora en este sentido la lectura de la segunda parte de una de las obras del profesor GENNARI (1997) que trata de "Prossemica e comunicazione educativa".

8. Es cierto, y de obligada referencia, que algunas disciplinas pedagógicas han conocido en los últimos veinte años un incremento de sus reflexiones en este sentido. La Historia de la educación, la Arquitectura Escolar, la Organización Escolar, la Pedagogía Comunitaria, la Pedagogía Urbana o la Educación Ambiental, son algunos de los campos que se han detenido en esta variable de forma especial (Trilla, 1986; ViñaO, 1993-1994, 1998; LuQUe, 1995; DOMÉNECH y ViÑas, 1997; Heras, 1997; CristóFOl y Comes, 1998; GutiÉrrez, 1998; Escolano, 2000; LuCio-Villegas, 2001). 
Pues bien, en esta dirección se sitúa la propuesta que hacemos y cuya idea central es la siguiente: si el espacio es el ámbito en el que se producen los hechos vitales, también los hechos y procesos educativos, es posible que existan algunas variables o vectores que dimensionan y explican la interdependencia que se establece entre los espacios y los sujetos, de manera que su conocimiento y manipulación podría proporcionarnos una optimización de los procesos que ahí se desarrollan. El espacio, desde esta perspectiva, no es sólo un determinado medio físico, un escenario para nuestros comportamientos, sino también un agente activo en el proceso educativo.

La concepción educativa de los individuos y de los colectivos, en consecuencia, debería recomponer también su perspectiva. Los sujetos, siendo el objetivo último del proceso educativo, han de ser comprendidos como personas que conviven con los espacios y se construyen en coderiva con sus ámbitos de referencia. La persona ya no es concebida solamente en base a un proceso de autorreconocimiento intraindividual sino más bien como comportamiento exteriorizado y construido también desde fuera, adoptando una forma elemental y primaria de desarrollo y de comunicación respecto del espacio en que se encuentra. De una autonomía o dependencia de la persona respecto del espacio pasamos a un concepto de pertenencia mutua.

Esta perspectiva reorienta también la práctica educativa, en cuanto que los espacios proporcionan oportunidades de acción, dando así un paso más allá del simple ejercicio de contextualización de la acción educativa.

\section{El LENGUAJE EDUCATIVO DE LOS ESPACIOS}

A partir de la orientación que venimos proponiendo mostramos algunos de los vectores que dan cuerpo al lenguaje educativo que propugnan los espacios. Nuestro propósito es comprender, analizar y reconstruir las formas socioeducativas que implementan en los procesos de formación, más allá de lo que ha venido siendo habitual en cuanto a formas sociotécnicas de expresión. Queremos mostrar que los espacios comportan un significado -simbólico, afectivo, comunicativo, etc-sobre formas topológicas, geográficas, arquitectónicas o físicas, traducible en términos educativos, pues despliegan una serie de comportamientos comunicacionales, sociales y culturales, en base a la interdependencia que mantienen con los sujetos.

\subsection{La experiencia territorial como comportamiento vital de las personas}

Hablar de la territorialidad humana, desde una perspectiva interdisciplinar, implica, por un lado, asumir una serie de conceptos o funciones que nos permiten comprender este término desde una perspectiva social y cultural, además de 
geográfica, y, por tanto, con posibilidades de asumir retos educativos 9 ; y, por otro, supone situarse en planteamientos basados en los enfoques socioculturales que aluden a la territorialidad en cuanto función del aprendizaje social y de influencias culturales (Bell y otros, 1996). Nos estamos refiriendo a funciones como la interacción y organización social -dominación y control, organización de actividades cotidianas, regulación de la agresión... - y la construcción de la identidad personal y grupal -la personalización, el apego y la apropiación a un lugar...- ${ }^{10}$.

Pensemos en la reacción que tienen muchos ciudadanos cuando comprueban que sus ciudades empiezan a llenarse de inmigrantes; o en los lugares públicos de los extrarradios de las ciudades que frecuentan los marginados sociales; o en la actitud de reclusión hacia la esquina del patio del colegio que llevan a cabo aquellos niños que han sido agredidos o maltratados. En el fondo de estas imágenes y realidades coexiste una serie de patrones de conductas y afectos que pueden ser interpretados desde la perspectiva territorial que los sostiene. La consistencia y personalización con que los sujetos regulan sus espacios de referencia tiene un marcado carácter social que, a su vez, permite interpretarlo desde una perspectiva educativa ${ }^{11}$.

Si observamos los territorios de referencia actuales, primarios como la familia, secundarios como la escuela, o públicos como las ciudades y sus calles, comprobamos que la territorialidad, en cuanto patrón que regula la organización social de las personas, puede ayudar a una coherente construcción de las identidades. El apego o sentimiento de pertenencia a un lugar, ese sentirse "como en casa" del que carecen aquellos a los que hemos aludido anteriormente, nos está indicando que, quizá vía regulación de los espacios, podamos ayudar a las personas a mejorar ese sentimiento territorial que les puede permitir comunicar a los demás sus necesidades básicas de relación y existencia ${ }^{12}$. Ello explica la necesaria tarea de devolver a las personas -inmigrantes, sin techo, marginados sociales, violentos callejeros

9. "...ya que en términos sociales el espacio se convierte en lugar, la idea abstracta de espacialidad adquiere dimensiones significativas, y la distancia define relaciones de proximidad o de deshumanización" (EsTÉBANEz, 2000, 191).

10. "...el sentido de identidad de grupo puede surgir del hecho de que las personas comparten el mismo lugar, lo que fomenta vínculos sociales, como han demostrado Cortés y Aragonés (1991), Valera y Pol (1994) y Valera (1997)" (VALERA y VIDAL, 1998, 142).

11. "...las dinámicas espaciales "conviven" - subyacen y soportan, sostienen y favorecen- con fenómenos y perspectivas teóricas, de uno y otro tipo, sobre "lo diferente", generando divisiones espaciales y "zonas de desarrollo del sujeto" -aquí y allí, lo público y lo privado, lo rural y lo urbano...-cargadas de significado y acción" (GARCía DEL Dujo y MuÑoz Rodríguez, 2002, 169).

12. "Las grandes ciudades son hoy sinónimo de libertad, de aceptación de las diferencias... pero son también símbolo de inseguridad, de anonimato, de despersonalización de las relaciones y de los intercambios" (SuBIRATS, 2002, 25-26). Este planteamiento que venimos trayendo nos invita a reconsiderar los espacios urbanos como espacios educativos capaces de reconducir las sociopatías urbanas. Las ciudades se configuran, desde el punto de vista de los sujetos que las habitan, como sistemas dinámicos donde se citan complejas interrelaciones que son las que conforman el estilo de vida de las personas y de la sociedad (RODRIGO y RODRIGO, 2000). En este sentido hemos de mencionar los numerosos 
incluso- la posibilidad de reconocer los espacios de convivencia y de reconocerse en ellos como paso previo para alcanzar su propio sentido y, quizá, a partir de ahí, reorientarles socioeducativamente: "el espacio aparece como unidad, como aglutinante de diversidad, como referente de un colectivo" (García, 1992, 401).

El nuevo medio ambiente opera como una especie de detonador. Su relación con el nuevo habitante se manifiesta dialécticamente como territorialidad nueva, y cultura nueva, que interfieren recíprocamente, cambiándose paralelamente territorialidad y cultura y cambiando al hombre. Cuando esa síntesis es percibida, el proceso de alineación va cediendo lugar al proceso de integración y de comprensión, y el individuo recupera la parte de su ser que parecía perdida (Santos, 2000, 280).

Y es que, desde el momento en que pretendemos mostrar el alcance que pueden llegar a tener los espacios como "agentes educativos", estamos demandando la presencia de un lenguaje que busca sus anclajes comunicativos en la propia realidad social y cultural donde las personas encuentran sentido a su existencia. La territorialidad, en principio, implica poner límites a un modo y manera de estar en los espacios, lo que se traduce no como aquello donde algo termina sino, más bien, el punto donde algo o alguien comienza a afirmar su propia existencia ${ }^{13}$.

Entre el espacio, físico y geográfico, social y cultural, y la actividad humana hay siempre un patrón sociocultural que ayuda a la identificación y desarrollo de la persona. Dicho de otro modo, el sentimiento despertado en las perşonas como consecuencia de la experiencia territorial no es tanto una cuestión espacial que reporta consecuencias sociales sino más bien un hecho sociológico con forma espacial. Aceptar esta idea como punto de partida de lo que puede ser un lenguaje educativo no es más que asumir, desde otro ángulo, uno de los procesos anímicos y sociales del individuo ${ }^{14}$.

La territorialidad implica, por parte de las personas, adquirir un sentimiento de situación e identificación en un lugar concreto y, por parte de los espacios,

estudios que existen desde la antropología urbana, destacando, entre otros muchos, la obra de HANNERZ (1993) que busca clarificar cuál es la línea identificativa de una antropología urbana.

13. Como indica Heidegger "la frontera no es aquello en lo que termina algo, sino, como sabían ya los griegos, aquello a partir de donde algo comienza a ser lo que es (comienza su esencia) [...]. De ahí que los espacios reciban su esencia desde lugares y no desde "el" espacio" (HeIDEGGer, 1994, 268). O en palabras de Bollnow, "el horizonte es a la vez lo que le permite al hombre encontrarse en el mundo como en su casa, vivir en él. Pues el hombre no podría vivir en un mundo infinito, y un campo visual sin fin le angustiaria, se encontraría desamparado. El horizonte engloba el espacio en torno al hombre para formar un mundo circundante finito y susceptible de ser abarcado" (Bollnow, 1969, 76).

14. Estos procesos permiten activar a las personas en sus espacios - de ahí la potencialidad educativa- hasta el punto de que terminan haciendo los espacios como algo suyo; la identidad de los espacios puede llegar a ser parte de la identidad de los propios sujetos merced a los significados que les reportan. "Cuando la población no participa en la transformación espacial, no sólo tiene lugar una producción del espacio de manera diferente sino que también se producen un tipo de relaciones humanas diferentes que dificultan la participación en la transformación paisajística, y, por ende, la constitución de ciudadanos" (Alguacil Gómez, 1998, 140). 
proporcionar elementos culturales traducibles en sistemas de significación que puedan facultar, a su vez, un lenguaje educativo. En definitiva, ayuda a interpretar la potencialidad educativa del espacio en base al grado y tipo de relación que se establece entre sujeto y espacio, rescatando así, para las consideraciones que puedan hacerse del espacio en clave educativa, ese patrón cultural que une y relaciona un lugar con un sujeto o grupo de sujetos.

\subsection{El significado sociocultural de los espacios}

Los espacios son, ante todo, significativos; constituyen uno de los referentes de sentido y explicación de la vida y de conformación de las personas merced a los significados que comportan: significados sociales, culturales, físicos, personales, afectivos... (Pellegrino, 2003). No tenemos más que observar las ciudades o pueblos en los que habitamos para comprobar la amalgama de significados que dichos espacios nos aportan: en unos casos agradables y en otros desagradables, más personales o quizá colectivos; unos espacios provocan topofobia y otros, en cambio, topofilia ${ }^{15}$. No nos interesa tanto resaltar los significados concretos, pues dependen del espacio de percepción de cada uno de nosotros, cuanto mostrar el hecho de que dichos significados suponen un bien social y cultural, educativo, de indudable valor, que hemos de descifrar.

Esto obliga a reordenar los espacios con el fin de que esos significados que tienen, material educativo primario, sean relevantes y expresivos en las personas de referencia y, por tanto, puedan constituir un eslabón más en la trama semióticoeducativa que puede llegar a establecerse entre los sujetos y los espacios. No se trata sólo de interpretar la significación como un aspecto relevante de las actividades educativas que se lleven a cabo en un espacio determinado sino también como una de sus funciones más importantes. "Es así porque los sistemas de actividad específicos conducen a los atributos específicos de lugares y entornos, explicando las causas de su diversidad y la resultante relación entre la cultura y el entorno" (Rapoport, 2003, 105).

Buscamos reorientar el significado de los espacios hasta el punto de poder interpretarlos como sistemas que crean estructuras sociales y físicas que permiten el desarrollo y la renovación del sujeto. Es así como podremos pasar de entender la vida de las personas dentro de los espacios a una concepción de los espacios

15. En ocasiones los significados son históricos, referidos a la memoria de los lugares; en otras, afectivos, en conexión directa con las emociones personales o colectivas de un determinado grupo; también podemos encontrarnos con significados culturales, en referencia a las tradiciones, costumbres, valores, o significados sociales, en alusión a formas de relación, de producción y reproducción, etc. Partimos de la no aceptación de un único sentido del espacio, pues no todas las personas que residen en un mismo lugar experimentan los mismos sentimientos (EYLES, 1985). 
como vida para las personas (Ramírez, 1999) ${ }^{16}$. La multiplicidad de las dimensiones semántico-educativas se extiende más allá del espacio físico, con el objetivo de alcanzar un semema global del espacio traducible en términos de lenguaje educativo. Los espacios y las experiencias que provocan no son procesos aislados, sino que se relacionan con otros procesos sociales, formando parte de una lógica común de relación que puede ayudar a la convivencia de diversos colectivos dentro de un mismo espacio (Gennari, 1984) ${ }^{17}$.

Estamos acostumbrados en educación a interpretar el significado sociocultural de los espacios como un cúmulo de signos sueltos e inconexos susceptibles de utilización en momentos puntuales; pensamos, en cambio, que la significatividad de los espacios facilita un trayecto educativo a través del cual los sujetos pueden ir más allá de la superficie fenoménica, considerando el espacio como generador y fundamento de su vida (Calvi, 2003). Si incidimos en la capacidad significativa y, por tanto, narrativa y de lenguaje, de la que pueden disponer los espacios, podremos comprender el sentido educativo que los propios sujetos otorgan a sus espacios cotidianos, lo que nos está invitando a plantear las cosas de otra manera y a pensar sobre la educación desde otra perspectiva.

Este planteamiento nos obliga a reconstruir los espacios, con el objetivo de permitir a los sujetos la posibilidad de cuestionar todo permanentemente, pasando así de respuestas de comportamiento estimuladas a respuestas narradas y significadas. Los lenguajes que aportan los espacios tradicionales de formación ayudan a construir la identidad social y cultural de los individuos, pero no sólo ellos deben ser los responsables en dicha tarea, sino que, del mismo modo, podemos favorecer que los sujetos asimilen la información desde fuentes diversas procedentes de las culturas significativas que aportan los espacios por los que se mueven y donde conviven.

Igualmente, resulta de especial interés para nosotros no tanto definir lo que es un símbolo sino, más bien, interpretar y analizar en los espacios influyentes qué es apropiado designar como símbolo, para poder estimular y diferenciar procesos de pensamiento y de actuación de un sujeto en una cultura. El análisis simbólico pone de manifiesto los asuntos más importantes de la expresión humana, ya que tienen su origen en una convención basada en el libre albedrío de quienes los crean y los reciben. Más allá de la dimensión puramente física, los significados socioculturales de los espacios poseen una dimensión psicosocial que coadyuva la

16. Esta diferencia entre el espacio en sentido geométrico o físico y el espacio vivido nos recuerda el concepto de "espacio hodológico", concepto que alude a la manera como la persona considera su espacio desde el punto de vista de sus posibilidades de comportamiento (Bollnow, 1969).

17. En el lado contrario nos encontramos con los denominados "no lugares", "espacios del anonimato", espacios que tienen que ver con sujetos no identificados, no socializados ni localizados más que "a la entrada y a la salida". Espacios que se asemejan más bien a un gran paréntesis que acoge a los individuos, formando así conjuntos de paréntesis, heterotopías (AuGÉ, 1998b). 
construcción de la identidad de un determinado grupo en un entorno concreto, objetivo de los procesos primarios de formación (Low, 2003).

No se trata de justificar cada movimiento, cada forma, cada detalle físico al que intentamos otorgar sentido, sino más bien, al estilo del movimiento moderno arquitectónico que encabezaba Le Corbusier, ver cómo se articulan los espacios en propuestas globales, de ocupación del espacio, buscando relacionar las estructuras físicas con planteamientos globales de formas de vivir y entender los espacios. Para comprender su naturaleza hay que descubrir si el lugar actúa de significante en los diálogos, en las vivencias y relaciones que allí se establecen (Le Corbusier, 1979).

Buscamos el interés por el significado, a través del sentido y representación social de los espacios, obviando al individuo como punto de partida. De esta forma, abrimos una amplia gama de posibilidades educativas, que no arrancan de la subjetividad del individuo sino más bien de la interdependencia entre el sujeto y el espacio. El sujeto actúa de distinta manera en espacios diferentes y cada espacio necesita y permite un modo de educar y de vida distinto según sus peculiaridades sígnicas ${ }^{18}$. El hombre, además de adaptarse al medio como lo hace el resto de animales, necesita construir discursos, narraciones acerca del espacio que le den significación, emotiva y racional. La función del espacio es precisamente hacer de plataforma para poder activar ese lenguaje.

\subsection{El elemento comunicacional de los espacios}

Si algo caracteriza a los espacios, vistos desde el punto de vista del sujeto implicado, es su capacidad de generar comunicación (Bakis, 1990). La posibilidad o no de comunicación supone no sólo uno de los componentes fundamentales del espacio sino su propia naturaleza ${ }^{19}$. En él hay tiempo, gentes, significados, y, por tanto, comunicación.

Estamos pensando en una interpretación de los procesos formativos no tanto en base a la transmisión de contenidos y conocimientos apoyados por la presencia de elementos comunicacionales adjuntos sino más bien como procesos insertos en las propias raíces de las tramas comunicacionales que se establecen entre el sujeto y los espacios de referencia. Así modificamos la disposición de las dos partes, sujeto y espacio, y concebimos, por un lado, la trama comunicacional como

18. Hay espacios que motivan, otros que inhiben; los hay que socializan y otros que aíslan. Y, del mismo modo, hay sujetos motivados o desmotivados, aislados o vinculados, según los espacios vitales y de convivencia que practican. El estudio y la interpretación de las circunstancias vitales en clave de espacios nos aporta un elemento que nos ayuda a inhibir determinados comportamientos o, por el contrario, estimular otros vía espacios de referencia.

19. Interprétese bien esta expresión. No se trata de entender la competencia comunicacional de los espacios en los mismos términos que el lenguaje humano sino de mostrar la posibilidad de interpretar los espacios en términos comunicacionales, "cuasi-personales", pues interpelan, conversan con los sujetos. 
proceso en el que el sujeto comparte cosas con el espacio, y, por otro, la educación apoyada no sólo en procesos de interacción comunitaria, sino también en procesos de creación de situaciones comunicacionales.

Esta modificación en la disposición tanto de los espacios como de los sujetos implica aceptar ideas que, en principio, pertenecen al mundo de lo humano, como son las que giran en torno a la competencia comunicativa ${ }^{20}$. Coincidimos en este sentido con el profesor Sosa, aunque él lo exponía para argumentar principios éticos, en la posibilidad de invertir el orden y otorgar mayor validez a la función expresiva de la comunicación, frente a su función argumentativa, aceptando la conciencia de interdependencia entre los elementos espaciales y humanos a partir de la posibilidad de manifestación de una competencia comunicativa por parte del espacio.

Sin dejar de reconocer que la comunidad ética es la comunidad de los seres racionales, en tanto que racionales y capaces de comunicación intersubjetiva, no hay razones para que los principios y las normas emanadas de una ética construida según la racionalidad comunicativa, tengan que recluirse, a su vez, sólo en las relaciones entre los seres humanos dialogantes... Cabría entender esa comunicación en términos de percepción, es decir, de disponibilidad y capacidad para ver y sentir... El medio siempre responde (Sosa, 2000, 320) ${ }^{21}$.

Nos apoyamos en un principio fundamental: no es posible no comunicarse (Bateson, 1984; Watzlawick, Beavin, y Jackson, 1997). Por ello, el espacio, entendido en toda su expresión afectiva, histórica, funcional, expresiva o cotidiana, puede llegar a poseer dicha propiedad, puesto que toda idea de comunicación viene amparada por un contenido, que lo aporta el propio espacio, y una relación que se establece con el sujeto de referencia. En este sentido, la acción comunicativa es concebida como acción o interacción simbólicamente mediada, orientada por una serie de normas básicas que afectan igualmente al sujeto como al espacio y que definen una serie de expectativas, tanto de comportamiento por parte del sujeto como de organización y orden por parte del espacio, que deben ser entendidas y reconocidas por ambas partes y dispuestas hacia la práctica educativa.

20. Hymes, en su libro On comunicative competence, introdujo el término "competencia comunicativa" para referirse al conocimiento y a la capacidad de una persona para utilizar todos los sistemas semióticos a su disposición como miembro de una comunidad sociocultural dada (HyMes, 1971).

21. Trasladado a nuestros intereses educativos, no se trata de poner el espacio en el centro del proceso, al más puro estilo de las posturas biocéntricas, pero tampoco de plantear la comunicación sólo y exclusivamente en términos interpersonales. El profesor Sosa optaba por hablar de uantropocentrismo débil" (sabio) en el que los intereses del hombre se ponderan en una visión más global, justificada y abierta del proceso comunicativo y, por ende, educativo (SOSA, 1995): "La comunicación es un intercambio de mensajes, de información, un diálogo del hombre consigo mismo y con su mundo. Su mundo son los demás hombres, las instituciones, los valores... y también su entorno. La comunicación es un proceso de interacción" (SOSA, 2000, 319). 
De esta forma nos estamos aproximando a lo que puede ser un lenguaje educativo entendido bajo la perspectiva de una dialogía social. Un diálogo donde la construcción de la persona y el desarrollo de su identidad, la reconstrucción de los espacios y la comunicación, están íntimamente unidos en un mismo proceso ${ }^{22}$. Unos y otros, los sujetos y los espacios, por medio del diálogo establecido, quedan comprendidos a través de una interdependencia comunicacional en nada mecánica ni determinista, sino netamente sociohistórica y cultural. Concebimos la relación en cuanto comunicación participada en el sentido de que son los espacios quienes fomentan estructuras o situaciones que permiten la participación e identificación de las personas.

Cuando en un pueblo, por ejemplo, modifican la arquitectura de la plaza principal, pública, es posible establecer una pedagogía desde una perspectiva dialógica. En primer lugar, esta perspectiva obliga a analizar el cambio de la plaza pública para saber qué ha cambiado en el comportamiento social, interactivo, entre edades, géneros y culturas. Porque supongo que está bien claro: los cambios en el espacio modifican las posibilidades de interacción social entre géneros, generaciones y culturas (Muntañola, 2004, 225).

Así las cosas, el lenguaje que planteamos queda presentado en términos de puesta en común, donde no sólo se emiten informaciones y argumentos enfocados hacia el individuo, sino que también estamos ante un campo de negociación en el que el espacio, además de recibir información, transmite y forma mediante un código, admitiendo un cierto relativismo cultural y posibilitando que en la acción educativa pueda intervenir como elemento primordial (Castro, 1999). Es la manera de dar cabida a aspectos relacionales, de contenido y circunstanciales, donde existe simetría y complementariedad, o al menos se debe perseguir, entre los sujetos actores de la situación y el lugar mismo de la acción, dando origen a prácticas concretas insertas en un espacio que manifiesta su significado.

\section{NOTAS PARA LA PRÁCTICA EDUCATIVA}

La finalidad de este planteamiento, lo hemos ido indicando, es reinterpretar un lenguaje con el fin de formular la práctica socioeducativa desde otra perspectiva. De un sentido abstracto del espacio pasamos a una concepción adherida a la acción humana y, en consecuencia, a la acción educativa. Y son muchos los ámbitos concretos en que este planteamiento puede y debe tener cabida. En esta ocasión vamos a mencionar, a modo de epílogo, uno que consideramos piedra angular: la acción

22. “Un diálogo auténtico crea, lenta pero firmemente, la competencia cívica que está a la base de la forma urbana de la ciudad. Se trata de un diálogo cívico que enlaza a las generaciones y está transido de historia y de tradición; un diálogo, en suma, que crea lugares" (RAMírez, 1999, 20). 
política socioeducativa y su implicación para la construcción de una sociedad intercultural $^{23}$.

Sin una relación estrecha, sin una íntima conexión y vinculación entre la política, la acción educativa y los espacios de referencia, algunos de los retos que plantea la sociedad pueden ser interpretados y tratados de manera insuficiente. Cuántas veces en educación, y en cultura, debido precisamente a una interpretación del territorio reducida a enfoques meramente políticos y jurídico-administrativos, se toman decisiones homogéneas y uniformes, trasladándolas miméticamente de unos ámbitos geográficos a otros, de unos niveles a otros, de unos contextos a otros. Si en los espacios es donde conviven las redes de acción y relación de las personas, donde se ubica el tejido social que pone de manifiesto las necesidades vitales y sociales de los individuos y los colectivos, parece lógico que sea ahí donde se pueda situar el capital formativo que deben preconizar las políticas educativas.

Educar, desde una concepción primaria de los procesos, puede interpretarse a través de la manipulación de los espacios de referencia y esto, a su vez, puede entenderse en el sentido de decisión y acción política. De lo contrario, estaremos defendiendo postulados homogéneos y descarnados, carentes del lenguaje que conforma la dimensión espacial de la acción humana ${ }^{24}$. Esto invita a superar la tesis de la nulidad o incluso del peligro que de entrada plantean las políticas educativas en clave de espacios. Buena parte de las acciones desarrolladas en política socioeducativa toman a los agentes personales como únicos responsables de las mejoras propuestas, ignorando que la manipulación de espacios, territorios y situaciones donde se asientan las colectividades pueden y deben formar parte también de un concepto más amplio de política socioeducativa.

Planteamos concebir la política como "momento de calificación del obrar humano" (Gennari, 1998, 53) en donde el sujeto hace real su vocación y anhelo de sentirse situado, realizado, identificado en un espacio, entendiéndolo como ámbito de compromiso donde se asegura la mejora y transformación social y cultural de todos aquellos que "llegan nuevos y son menos" a un lugar determinado. Estamos pensando en los inmigrantes y en la posibilidad, a través de las políticas territoriales socioeducativas, de salvaguardar y apreciar la diversidad y las diferencias, las identidades y las pertenencias, en un mismo ámbito de convivencia. La dignidad de la política debe arrancar desde ahí y desde ahí también es desde donde han de reconocerse las diversas culturas que hoy conviven.

No existe un solo relato identitario sino muchos relatos provenientes de diversos lugares (Hetherington, 1998). Estamos necesitados de pensar cuáles son

23. Coincidimos nuevamente con el profesor Muntañola en que las relaciones entre espacio y educación son múltiples y complejas: "lo que normalmente se estudia es la arquitectura de las instituciones educativas. Sin querer ofender a nadie, esta relación (aunque muy significativa) no es la más importante del tema" (MunTAÑola, 2004, 221).

24. Conectamos así con los planteamientos que subyacen en el debate entre lo local y lo global (Ball, 2002; Borja y Castells, 1997; Brugué y Goma, 1998; Braslavsky y Gvirtz, 1999; Subirats, 2002). 
nuestros sitios, qué espacios socioculturales tienen unos y otros y, sobre todo, qué posibilidades existen de postular interdependencias en base a argumentos espaciales comunes pues, en última instancia, todos estamos inmersos en un cruce de pertenencias territoriales. Ello invita a efectuar una propuesta donde las bases estén apoyadas en la reconstrucción de los espacios de cara a que faculten la convivencia, no desigual, de diversidades culturales, potenciando y favoreciendo a la vez tanto la creación como la integración de culturas. El lenguaje que proporcionan los espacios puede ayudar a educar en la diversidad y a dar cauce a muchos de los desajustes culturales que hoy tenemos en nuestros lugares comunes.

\section{BIBLIOGRAFÍA}

AA.VV. (2000) Pedagogías del Siglo XX. Barcelona, Cisspraxis.

ALGUACIL GÓMEZ, J. y MONTAÑÉS SERRANO, M. (1998) La participación ciudadana en la transformación del paisaje urbano, en AA.VV. El paisaje urbano en el marco de la sostenibilidad. Segovia, Asociación para el estudio del paisaje/CNEAM, 139-156.

ARENDT, H. (1996) La condición bumana. Barcelona, Paidós.

ASENSIO, J. M. (2004) Una educación para el diálogo. Barcelona, Paidós.

Augé, M. (1998a) Hacia una antropología de los mundos contemporáneos. Barcelona, Gedisa.

- (1998b) Los no lugares. Espacios del anonimato. Barcelona, Gedisa.

BACHELARD, G. (1965) La poética del espacio. México, FCE.

BAKIS, H. (1990) Communications et territoires. Paris, La Documentation Française.

BALL, S. J. (2002) Grandes Políticas, un mundo pequeño. Introducción a una perspectiva internacional en las políticas educativas, en NARODOWSK, M. (comp.). Nuevas tendencias en políticas educativas. Estado, mercado y escuela. Barcelona, Granica, 103-128.

BATESON, G. (1984) La nueva comunicación. Barcelona, Kairós.

BAUMEN, U. (2001) En busca de la politica. Buenos Aires, FCE.

BELL, P. A. y otros (1996) Environmental psychology. Forth Worth, Harcourt Brace.

BOLLNOW, O. F. (1969) Hombre y espacio. Barcelona, Labor.

BORJA, J. y CASTELLS, M. (1997) Local y Global. La gestión de las ciudades en la era de la información. Madrid, Taurus.

BRASLAVSKY, C. y GVIRTZ, S. (1999) La ciudad, espacio de mediación entre la macro y la micropolítica, en AA.VV. Por una ciudad comprometida con la educación, vol. 1. Barcelona, Ajuntament de Barcelona, Institut d'Educació, 507-531.

BRugué, Q. y GOMA, R. (1998) Gobiernos locales y politicas públicas. Barcelona, Ariel.

CALVI, E. (2003) Proyecto y relato. La arquitectura como narración, Arquitectonics. Mind, Land \& Society, 4, 53-69.

CAstillejo, J. L. y otros (1994) Teoría de la Educación. Madrid, Taurus.

CASTRO, R. (1999) Retos y oportunidades de la comunicación para el cambio ambiental, Ciclos. Cuadernos de comunicación, interpretación y educación ambiental, 5, 4-8.

COlOM CAÑEllas, A. J. y SUREDA, J. (1981) Hacia una teoria del medio educativo. (Bases para una pedagogía ambiental). Palma de Mallorca, Servicio de Publicaciones Universidad de Palma de Mallorca. 
CORTÉs, B. y ARAGONÉs, A. (1991) Identidad social y territorio. Análisis cualitativo del discurso sobre dos espacios comarcales de la comarca de Madrid, en DE CASTRO, R. (coord.). Psicología Ambiental: Intervención y evaluación del entorno. Sevilla, Arquetipo.

CRISTÓFOL, A. y COMES, P. (1998) El tiempo y el espacio en la Didáctica de las ciencias sociales. Barcelona, Graó.

DELGADO, M. (1999) El animal público. Barcelona, Anagrama.

DOMÉNECH, J. y VIÑAS, J. (1997) La organización del espacio y del tiempo en el centro educativo. Barcelona, Graó.

Escolano Benito, A. (2000) Tiempos y espacios para la escuela: ensayos bistóricos. Madrid, Biblioteca Nueva.

ESTÉBANEZ ÁlVAREZ, J. (2000) La Geografía Humanística, en AA.VV. Lecturas geográficas, vol. I. Madrid, Editorial Complutense.

EYLES, J. (1985) Senses of place. Londres, Silverbook Press.

FULLAT I GENIS, O. (2000) Filosofía de la Educación. Madrid, Síntesis.

GARCíA, J. L. (1992) El uso del espacio: conductas y discursos, en GonZÁlez ALCANTUS, J. A. y GONZÁLEZ DE MOLINA, M. (eds.). La tierra. Mitos, realidades y perspectivas. Barcelona, Anthropos y Diputación Provincial de Granada, 398-412.

GARCÍA CARRASCO, J. (1992) La perspectiva ecológica y el discurso teórico de la educación, Teoría de la Educación. Revista Interuniversitaria, 4, 54-72.

- (2004) La comprensión de la vivienda como un dominio vital de los humanos, Revista Española de Pedagogía, 228, 229-256.

García CARRASCo, J. y García Del Dujo, A. (2001a) Teoría de la Educación. Procesos primarios de formación del pensamiento y la acción. Salamanca, Ediciones Universidad.

- (2001b) La teoría de la educación en la encrucijada, Teoría de la Educación. Revista Interuniversitaria, 13, 15-43.

García del Dujo, A. y MuÑoz Rodríguez, J. M. (2002) Pedagogía de los espacios: una interpretación espacial de los fenómenos y problemas socioeducativos, en HERNÁNDEZ, J.

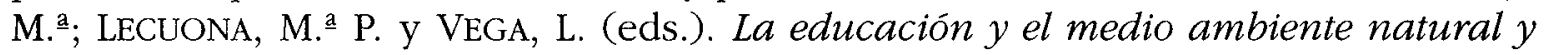
bumano. Salamanca, Ediciones Universidad, 167-179.

- (2004) Pedagogía de los espacios. Esbozo de un horizonte educativo para el siglo XXI, Revista Española de Pedagogia, 228, 257-278.

Gennari, M. (1984) Pedagogia e Semiótica. Brescia, La Scuola.

- (1997) Pedagogía degli ambienti educativi. Roma, Armando editore.

- (1998) Semántica de la ciudad y Educación. Pedagogía de la ciudad. Barcelona, Herder.

GOULD, S. J. (2003) La falsa medida del hombre. Barcelona, Crítica.

GUTIERREZ PÉREZ, R. (1998) La estética del espacio escolar. Barcelona, Oikos-Tau.

HALL, E. T. (1973) La dimensión oculta. Enfoque antropológico del uso del espacio. Madrid, Instituto de Estudios de Administración Local.

HANNERZ, U. (1993) Exploración de la ciudad. Hacia una antropología urbana. México, FCE.

HEIDEGGER, M. (1994) Conferencias y artículos. Barcelona, Ediciones del Serbal.

HERAS MONTOYA, L. (1997) Comprender el espacio educativo. Málaga, Aljibe.

HYMEs, D. H. (1971) On communicative competence. Philadelphia, University of Pennsylvania.

KAPLÚn, M. (1998) Una pedagogía de la comunicación. Madrid, Ediciones de la Torre.

LE CORBUSIER (1979) Precisiones respecto a un estado actual de la Arquitectura y del Urbanismo. Barcelona, Poseidón.

LOw, S. (2003) The Anthropology of space and place: Locating Culture. Oxford, Blackwell Publishers. 
LUCIO-VILLEGAS, E. (2001) Espacios para el desarrollo local. Barcelona, PPU.

LUQUE DOMÍNGUEZ, P. A. (1995) Espacios educativos: sobre la participación y transformación social. Barcelona, EUB.

MORAles, J. R. (1999) Arquitectónica. Sobre la idea y el sentido de la arquitectura. Madrid, Biblioteca Nueva.

- (2004) Arquitectura, educación y dialogía social, Revista Española de Pedagogía, 228, 221-228.

Pellegrino, P. (2003) Le sens de l'Espace. Les Grammaires et les Figures de l'Entendue. Livre III. Paris, Anthropos.

RAMÍREZ, J. L. (1999) La construcción de la ciudad como lógica y como retórica. Los dos significados de la ciudad, Astralago. Cultura de la Arquitectura y la ciudad, 12, 9-24.

RAPOPORT, A. (2003) Cultura, Arquitectura y Diseño. Barcelona, UPC.

REDONDO GARCía, E. (1999) Educación y comunicación. Barcelona, Paidós.

RODRIGO, P. y RODRIGO, A. (2000) El espacio urbano. Madrid, Síntesis.

ROMAÑÁ BLAY, T. (1994) Entorno físico y educación. Reflexiones pedagógicas. Barcelona, PPU.

- (2004) Arquitectura y educación: perspectivas y dimensiones, Revista Española de Pedagogia, 228, 199-220.

SANTOS, M. (2000) La naturaleza del espacio. Técnica y tiempo. Razón y emoción. Barcelona, Ariel.

SOSA, N. M. (1995) Ecological Ethics as an Ethics of Physical and Moral Survival. Towards a Morality of All-Embracing Communication and Solidarity, en SITTER-LIVER, B. (ed.). Culture within Nature. Culture dans la Nature. Basel, Swiss Academy of Humanities and Social Sciences/Unesco, 87-100.

- (2000) Ética Ecológica: entre la falacia y el reduccionismo, Laguna. Revista de Filosofia, VI, 318/320, 307-327.

SUBIRATS I HUMET, J. (2002) Gobierno local y educación. Barcelona, Paidós.

Sureda, J. y COlom Cañellas, A. J. (1989) Pedagogía Ambiental. Barcelona, Ceac.

TODD, E. (1999) La ilusión económica. Sobre el estancamiento de las sociedades desarrolladas. Madrid, Taurus.

TRILlA, J. (1986) Ensayos sobre la escuela: el espacio social y material en la escuela. Barcelona, Laertes.

- (coord.) (2002) El legado pedagógico del siglo XX para la escuela del siglo XXI. Barcelona, Graó.

- (2004) Hacer Pedagogía hoy, en Congreso Internacional "Pedagogia y Educación en el Siglo XXI. Madrid, Universidad Complutense. Inédito. Documento fotocopiado.

VALERA, S. (1997) Estudio de la relación entre el espacio simbólico urbano y los procesos de identidad social, Revista de Psicología Social, 12, 17-30.

VALERA, S. y POL, E. (1994) El concepto de identidad social urbana. Una aproximación entre la Psicología Social y la Psicología Ambiental, Anuario de Psicologia, 62, 5-24.

VAlerA, S. y VIDAL, T. (1998) Privacidad y territorialidad, en ARAGONÉS, J. I. y AMÉRIGO, M. a Psicología Ambiental. Madrid, Pirámide.

VIÑAO FRAGO, A. (1993-1994) Del espacio escolar y la escuela como lugar: propuestas y cuestiones, Historia de la Educación. Revista Interuniversitaria, 12/13, 17-74.

WATZLAWICH, P.; BEAVIN, J. H. y JACKSON, D. D. (1997) Teoría de la comunicación bumana. Interacciones, patologias y paradojas. Barcelona, Herder.

WulfT, Ch. (2004) Antropología de la educación. Barcelona, Idea.

ZUBIRI, X. (1996) Espacio. Tiempo. Materia. Madrid, Alianza. 